\title{
Los costos de la cárcel ${ }^{1}$
}

\author{
The costs of prison
}

Os custos da prisão

Les coûts de la prision

入狱的费用

\section{Fabián Bernal \\ Universidad Nacional de Colombia - Colombia}

Revista Derechos en Acción ISSN 2525-1678/ e-ISSN 2525-1686

Año 5/No 16 Invierno 2020 (21 junio a 20 septiembre), 236-254

DOl: https://doi.org/10.24215/25251678e422

Recibido: 01/05/2020

Aprobado: 01/07/2020

Resumen: El contexto carcelario se debe concebir como un orden social desde el cual se ejerce control poblacional, a través de diversos mecanismos, estos implican una maximización de estrategias de vigilancia, donde las diferentes formas de control convergen en el disciplinamiento constante de las subjetividades. Estos mecanismos hacen que la cárcel funcione como una maquina sustentada por quienes la habitan. Memorias de las cárceles argentinas, colombianas y de estadounidenses son ejemplos de esta modalidad de control, sin embargo, pese a que sus dinámicas de funcionamiento interno son diferentes, no escapan a una dimensión económica del control poblacional, donde las personas

\footnotetext{
1 Un borrador inconcluso de este ensayo fue discutido y abordado en las mesas de trabajo de las XIII Jornadas de Sociología de la Facultad de Ciencias Sociales en la Universidad de Buenos Aires durante el 2019 y en la II Jornadas de Sociología de la Universidad Nacional de Mar del Plata en el mismo año.

2 Politólogo y Magister en Derechos Humanos y Derecho Internacional Humanitario de la Universidad Nacional de Colombia. Candidato a Magister en Historia y Memoria de la UNLP. Actualmente trabaja para la Comisión Provincial por Memoria Provincia de Buenos Aires. (ORCID: https://orcid.org/ 0000-0001-5645-2995).
} 
privadas de su libertad son el insumo básico para el funcionamiento de la máquina, y las destinatarias de las consecuencias subjetivas de la misma. Este ensayo se basa en memorias que dan cuenta de la vivencia de quienes fueron parte e insumo de dicha maquinaria, quienes desde sus recuerdos muestran un retrato del significado y costos del encierro más allá de las fronteras.

Palabras clave: Cárcel, Memoria, Gobernabilidad, Costo subjetivo, Costo económico

Abstract: The prison context can't be conceived as a homogeneous whole, but rather, as a social order from which population control is exercised, through various mechanisms, these imply maximization of surveillance strategies with various fines, However, the different forms of control converge in the constant discipline of subjectivities. These mechanisms make the prison work as a machine independent of those who inhabit it, but supported by themselves. The stories of life in Argentine, Colombian and American prisons are examples of this type of control, however, although their dynamics of internal functioning are different, they do not escape an economic dimension of population control, where people deprived of Their freedom is the basic input for the operation of the machine, and the recipients of the subjective consequences of it. This essay is based on memories that account for the daily experience of those who at one time were part and input of said machinery, who from their memories identify a clear portrait of the meaning and costs of confinement beyond borders.

Keywords: Jail, Memory, Governance, Subjective cost, Economic cost.

Resumo: 0 contexto prisional deve ser concebido como uma ordem social desde a qual é exercido o controlo da população, através de diversos mecanismos, o que implica uma maximização das estratégias de vigilância, onde as diferentes formas de controlo convergem na disciplina constante das subjectividades. Estes mecanismos fazem a prisão funcionar como uma máquina apoiada por aqueles que a habitam. Memórias das prisões argentinas, colombianas e americanas são exemplos deste tipo de controlo, no entanto, apesar de a sua dinâmica interna de funcionamento ser diferente, não escapam a uma dimensão económica de controlo populacional, onde as pessoas privadas da sua liberdade são o sustento básico para o funcionamento da máquina, e 
as destinatárias das consequências subjectivas da mesma. Este ensaio baseia-se em memórias que dão conta da experiência de quem fizeram parte e sustento dessa maquinaria, quem desde suas memórias mostram um retrato do significado e custos do confinamento além das fronteiras.

Palavras-chave: Prisão, Memória, Governança, Custo subjectivo, Custo económico

Résumé: Le contexte carcéral doit être conçu comme un ordre social à partir duquel s'exerce le contrôle de la population, à travers différents mécanismes, ceux-ci impliquent une maximisation des stratégies de surveillance, où les différentes formes de contrôle convergent dans la discipline constante des subjectivités. Ces mécanismes font fonctionner la prison comme une machine soutenue par ceux qui l'habitent. Les mémoires des prisons argentines, colombiennes et américaines sont des exemples de cette forme de contrôle, cependant, malgré le fait que leur dynamique de fonctionnement interne soit différente, elles n'échappent pas à une dimension économique du contrôle de la population, où les personnes privées de liberté sont l'entrée de base pour le fonctionnement de la machine, et les destinataires des conséquences subjectives de celle-ci. Cet essai est basé sur des souvenirs qui rendent compte de l'expérience de ceux qui ont fait partie et ont contribué à ladite machinerie, qui à partir de leurs souvenirs montrent un portrait de la signification et des coûts de l'enfermement au-delà des frontières.

Mot-clés: Prison, mémoire, gouvernance, coût subjectif, coût économique

摘要: 监狱环境必须被视为一种社会秩序, 通过各种机制从那里实 行人口控制, 这意味着最大化了监视策略, 在这种监视策略中, 不同 形式的控制融合在主体性的不断规律中. 这些机制使监狱的工作就 像一台由居住者支持的机器. 阿根廷监狱, 哥伦比亚监狱和美国监 狱的记忆就是这种控制形式的例子，但是，尽管其内部运作机制有 所不同, 但它们并没有摆脱人口控制的经济层面, 在这些方面, 被剥 夺自由者是机器操作的基本输入, 以及主观结果的接受者. 本文基 于记忆, 该记忆描述了那些参与所述机器的人的经验, 并从他们的 记忆中展示了越境禁闭的意义和成本.

关键字: 监狱, 记忆, 治理, 主观成本, 经济成本 


\section{Introducción}

Vale la pena iniciar este abordaje de los recuerdos mencionando que -al igual que Maurice Halbwachs- este trabajo entiende la memoria como una labor de reconstrucción que se apoya en el presente para recuperar el pasado. Desde esta perspectiva, a través de los recuerdos y los olvidos de quienes en algún momento de su vida conocieron el encierro -desde adentro- voy a intentar poner de relieve sus estrategias de sobrevivencia, desde la perspectiva subjetiva y dejar que sean los recuerdos de -quienes me permito llamar- "las victimas carcelarias" quienes evidencien su verdadero significado.

En el transcurso de este escrito será posible conocer las vivencias de tres personas que en tiempos y lugares distintos tuvieron en común el dolor, el frio, el miedo, la angustia, pero sobre todo, que hoy comparten la fuerza de volver a ese pasado traumático y compartir sus recuerdos; para levantar una voz que pone en tensión y cuestiona la cárcel como aparato estatal para generar sufrimiento.

\section{II. ¿Historia o Memorias del encierro?}

Es importante aclarar que este trabajo no tiene la pretensión de construir una historia totalizadora encierro, sino más bien trasmitir que a través de las subjetividades de la memoria podemos abordar problemáticas sociales vigentes en todo tiempo y lugar.

Para comprender desde qué punto se abordaran los recuerdos del pasado, es importante mencionar que no haremos uso exclusivo del Modelo de investigación autosuficiente o documental, ni tampoco del Constructivismo radical como modelos de interpretación.

Este trabajo comprende que el Modelo de investigación autosuficiente o documental, cuya forma extrema es el positivismo; entiende que reunir pruebas y hacer aseveraciones referenciales con formas de reivindicación 
de verdad fundamentadas en esas pruebas, son las condiciones necesarias y suficientes de la historiografía. LaCapra (2005).

Y Tiene como características; (1) estricta separación u oposición binaria entre el sujeto y el objeto; (2) tendencia a fundir y confundir la objetividad y el objetivismo o la objetivación del otro; (3) identificación de la comprensión histórica con la explicación causal; (4) negación de la trasferencia o del problema que suscita el hecho de que el observador esté implicado en el objeto de observación; (5) exclusión o subestimación de la relación dialógica con el otro.

Su exageración positivista confina a la historiografía a aseveraciones constatativas o referenciales que implican reivindicaciones de verdad hechas por un observador acerca de un objeto de investigación netamente diferenciado. LaCapra (2005).

Desde esta perspectiva,

Para autores como BerelLang, hay que contar solo los hechos, pues de otra forma se recae en el discurso figurativo y la estilización (esteticismo). Y solo una crónica de los hechos tiene la autoridad de hacerlo, pues de otra forma uno se expone a los peligros de la narrativización y la relativización del entramado. La escritura literaria y toda clase de escritura histórica que aspira al estatuto de lo literario resultan especialmente objetables, porque la figura del autor se impone entre aquello que ha de representarse y la propia representación. White (2007).

Acorde a lo mencionado es válido aclarar que este trabajo no comparte esa visión, por lo que se verá más adelante. Por otro lado para el segundo enfoque, imagen negativa del primero -el constructivismo radical- "las aseveraciones que entrañan una reivindicación de verdad incumben en el mejor de los casos a los acontecimientos y tienen una importación limitada, incluso marginal. Lo esencial son los factores reformativos, figurativos, estéticos, retóricos ideológicos y políticos que "constituyen" las estructuras -relatos, tramas, argumentaciones, interpretaciones, 
explicaciones en las cuales las aseveraciones están incluidas y de la cuales extraen su sentido e importancia" LaCapra (2005). Desde este punto de vista citando a Frank Ankesrmit, LaCapra menciona que para el constructivismo radical "todo lo que es esencial e interesante en la escritura de la historia (en la teoría y en la práctica) no se halla en el nivel de las afirmaciones individuales, sino en el nivel de la política que los historiadores abrazan cuando eligen las afirmaciones que confieren individualidad a su pintura del pasado" LaCapra (2005). En relación a los dos modelos analizados, este trabajo comparte en cierto sentido la interpretación de Dominick LaCapra quien entiende la historia como "algo que entraña una tensa reconstrucción objetiva (y no objetivista) del pasado y un intercambio dialógico con él y con otras indagaciones sobre él, en el cual el conocimiento supone no solo procesamiento de información sino también efectos, empatía y cuestiones de valor". Desde esta perspectiva y en relación a la comprensión histórica, no debería contemplase la vivencia de una manera estrechamente cognitiva que solo implica el procesamiento de información”. LaCapra (2005). Sin embargo nos distanciamos de LaCapra en medida que "articular históricamente lo pasado no significa conocerlo "tal y como verdaderamente ha sido». La verdadera imagen del pasado transcurre rápidamente. Al pasado sólo puede retenérsele en cuanta imagen que relampaguea, para nunca más ser vista, en el instante de su cognosciblilidad". Benjamín (1989). Desde esta perspectiva consideramos más conveniente hablar de memorias subjetivas y de esta manera mantener en ellas sus pretensiones de seguir siendo relatos del pasado, recuperados desde el presente. Recuerdos de sucesos traumáticos, mas no una pretensión históricas de verdad; simplemente la de rescatar los recuerdos que configuraron subjetividades individuales en momentos traumáticos.

\section{Testigos tras las rejas}

"En latín hay dos palabras para referirse al testigo. La primera, testis, de la que deriva nuestro término "testigo", significa 
etimológicamente aquel que se sitúa como tercero (terstis) en un proceso o un litigio entre dos contendientes, ha pasado hasta el final por un acontecimiento y esta, pues, en condiciones de ofrecer un testimonio sobre él”. Agamben (2000). Es por esto que quienes han logrado salir del encierro son testigos que fueron atravesados por diversas violencias y que al hablar de ellas, dan cuenta de su condición de víctimas. Sin embargo -como es lógico pensar- para poder salir, primero hay que entrar, y este ingreso también tiene sus propias lógicas.

El encuentro con la cárcel es impactante desde el primer día, dado que el encierro es un universo paralelo, con reglas distintas al mundo en libertad, reglas que quien ingresa por primera vez -en el mayor de los casos- desconoce por completo. En palabras de Primo Levi podemos definir que el ingreso se ve como un choque por la sorpresa que supone.

El mundo en el que la persona se ve precipitada es efectivamente terrible pero, además, indescifrable; no se ajustaba a ningún modelo, el enemigo está alrededor, pero dentro también, el "nosotros" pierde sus límites, los contendientes no son dos, no se distingue una frontera, sino muchas y confusas a la vez, tal vez innumerables, una entre cada uno y el otro. (Levi 2015).

El primer día en la estación de policía no pude dormir por el frio, y cuando me entere que iba para la Cárcel Modelo, menos pude dormir. Yo ya conocía la modelo, porque mi papa estuvo ahí. Estaba asustado, pero también pensativo, fuera como fuera no iba a dejar que pasara nada, si me pasaba era peleando. Al llegar a la modelo nos llevaron a un calabozo, es un lugar donde están los que llegan de todas las URI (Unidades de reacción inmediata), ladrones, asesinos, había por lo menos 20. Siempre hay mucho ruido, gritos y una frase para los nuevos "échelo aquí para violarlo". Uno no está acostumbrado a que se lo griten 20 personas. El corazón me palpitaba, pero no lo demostraba físicamente, yo me preguntaba "¿en qué momento se me lanzan, en que momento me toca?", estaba siempre a la defensiva, pero sin demostrarlo. Harold-Colombia 
Al momento de la detención entre 10 me tiraron al piso, me requisaron todo, me dejaron con una mano esposada a la silla y sin poder ir al baño, estaba que me orinaba, tuve que orinar delante de la guardia, era todo muy humillante. A una la meten en unos calabozos horribles, tenía tanto miedo. Beatriz- EE.UU

El momento en que fui detenida, yo estaba con mi hermano, tenía la conciencia de que todo había terminado, por lo tanto todo lo que pasara no importaba, si fuera bueno o malo, si me condenaban a muerte no importaba, mi sensación era de "termino mi vida este día". Era un lugar horrible, pero no importaba. La unidad 4 de Bahia Blanca era como una casa vieja, las celdas eran horribles. Cuando llegue a la unidad 8 conocí una cárcel de verdad, los buzones donde me llevaron, nunca los volví a ver, era tan horribles, oscuros y chicos que solo podía estar parada. La policía no quería que yo estudiara, por eso primero me colocaron en el buzón y luego en el peor pabellón a ver qué pasaba. Alicia-Argentina

Esta primera impresión es sin duda la antesala al sistema de disciplinamiento en el que las subjetividades empiezan a ser degradas.

Habíamos 10 personas en la celda que me tocó a mí, estaba en muy mal estado, los inodoros llenos de mierda. Solo había cuatro planchas para dormir, los demás dormíamos en el piso o al lado del inodoro. Estábamos todos acumulados como perros. El frio me mato, se me metía en las costillas, no me podía acomodar, estuve mirando la reja toda la noche, veía pasar las ratas de $30 \mathrm{~cm}$. Habían unos bichos que no conocía, se llaman chinches, son tipo pulga pero se meten en la piel y le chupan la sangre hasta que pica, me levante con esa piquiña, así fue que conocí los chinches. Harold - Colombia

Las cárceles de New Yersey y Hudson son un infierno, es lo peor que puede pasar un ser humano, siempre me trataron como a una estatal y a las estatales ${ }^{3}$ les pegan,

3 El uniforme para las que están en la cárcel estatal es gris y es naranja para las federales, el de las estatales es horrible y de la peor calidad. En federal se tiene un estrato un poco más alto. 
les escupen, tienen que dormir con las ratas, les hacen millones de cosas...Me toco dormir en el piso, con ratas, cucarachas y viendo cada día como entraban cada clase de drogadictas y verlas sufrir e implorar por droga. Beatriz- EE.UU

Podría decirse que este tipo de iniciaciones tienen por objeto mostrar a quien ingresa; no solo como se va a ver obligado a adaptarse para sobrevivir, sino también buscan reducir con cualquier tipo de posible resistencia desde el inicio. "Mas que un simple forastero que inicialmente busca la aceptación o tolerancia por parte del grupo" Schütz (2015), "el recién llegado es como un adversario por definición, sea cual sea la etiqueta que tenga adjudicada, y debe ser abatido pronto, antes de que se convirtiese en ejemplo o en germen de resistencia organizada" Levi (2015). Esta administración de disciplinamiento no solo es repartida por los funcionarios oficiales de la institución, sino también por un funcionario que en palabras de Primo Levi, intenta conservar -si se puede denominar así- algún tipo de "privilegio".

En este punto, el choque contra la realidad [...] coincide con la agresión -ni prevista ni comprendida- de un enemigo nuevo y extraño, el prisionero funcionario que, en lugar de cogerte la mano, tranquilizarte, enseñarte el camino, arroja sobre ti dando gritos... quiere domarte, quiere extinguir en ti la chispa de dignidad que tal vez todavía conserves y que él ha perdido. Levi (2015).

En la modelo los patios son bloques de 4 pisos con 4 pasillos de cada lado, se puede ver el otro patio pero están separados por una reja, no se mezclan: Hay alrededor de 800 o hasta 1000 personas por patio, haga de cuenta todas esas personas gritando "échelo échelo aquí para violarlo"... la entrada a patio, ese trayecto entre la recepción y el patio es todo de maltrato, palo, golpes, lo que sea, Le dan palo a los que llevan la contraria, una vez un guardia me dijo: "aquí no tratamos con un jardín de niños, son todos delincuentes" no van a entender con buenas palabras... Al llegar al patio el guardia me 
entrego a 4 pasilleros (todos más grandes que yo) uno no sabe con quién carajos va, ellos me metieron en una celda y me preguntaron porque venía... yo seguía con susto... les dije toda la verdad. Harold - Colombia

En la cárcel supe lo que eran las "kiking" son las drogadictas a las que les llega el momento en que la droga ya no les entra, yo estaba en el suelo durmiendo y llegaba alguna de ellas a morbosearme -era horrible- yo pedía clemencia, pedía que alguien me ayudara. Me quisieron violar dos veces, casi todas son lesbianas y uno no puede hacer nada, se juntan negras y blancas, ellas tienen sus métodos para hacer las cosas, fue terrible. Beatriz- EE.UU Cuando me llevaron a población, me impresionaron los silbidos de chicas, me decían "vení, que buena que estas". Era un ambiente muy pesado, gente que estaba acostumbrada a defenderse de la violencia de la policía y de las mismas compañeras. En la celda me dijeron "que vas a hacer ahora si te violamos entre todas". Alicia-Argentina

O también es probable, que:

Todas las intolerancias, la hostilidad contra quien ingresa tenga en esencia origen en el intento inconsciente de consolidar el "nosotros" a expensas de los otros, para crear paradójicamente la solidaridad entre oprimidos, cuya ausencia es fuente adicional de sufrimiento [...], esto complementado por un sentimiento de envidia, porque pareciese tener olor al afuera Levi (2015).

Sin embargo, vale la pena aclarar que esta administración de disciplina, es parte de la lógica de la institución total y no libre albedrío de quien es "depositado" en ella.

Acorde a lo anterior, y con el propósito de no banalizar el mal -parafraseando a Hannah Arendt- se podría decir recurriendo a la literatura que es posible vislumbrar que a través de las experiencias particulares de los individuos -en La colonia penintenciariala de Kafka-

La maquinaria ejecutora de dicha operación técnica cada vez más sustraída de la intervención directa de los 
hombres no funcionaría sin el individuo y su conducta cotidiana. "Mire ese aparato -exclamo el oficial kafkiano de la Colonia Penitenciaria-, hasta ahora debía accionarse a mano, pero a partir de ahora el aparato funciona solo". Traverso (2001).

Lo anterior, si bien describe un proceso de degradación -al parecer sin sujeto-, donde la ejecución de la pena es confiada a una máquina, sin que la víctima pueda mirar a su verdugo real, muestra que la activación de dicha maquinaria tiene su raíz en "una cadena de conductas individuales que configuran un orden social donde la actividad distinta de diferentes actores se integra en un todo coherente, permitiendo el desarrollo, consciente o inconsciente, de ciertos fines o funciones globales" Goffman (1991) y en el caso de la cárcel, estos fines implicaran un costo que recae sobre sus propios destinatarios.

\section{Los costos del encierro}

Hasta aquí hemos hablado de una "tecnocracia carcelaria" en la medida que quienes la ejercen son funcionarios despojados de todo tipo de ideología política y especializados -por la experiencia cotidiana y enseñanzas heredadas de funcionarios pasados- en la administración y gestión del castigo y el control.

En las cárceles se desayuna entre 5:30 y 6, se almuerza entre 9 y 11 y se come entre 14 y 15 . Había una comida que se le conocía como pasta bomba, fue la única vez que comí eso "pasta con salchicha y huevo picado "cuando lo comi termine demostrando que estaba acoplado a la situación, sin estarlo. Uno se acopla o se acopla. Harold - Colombia

Desde la mañana nos levantaban a las 3 am, hacían el conteo de la celda, y luego se recibía el desayuno, yo solo recibía los huevos -cuando daban-. Toda la comida me producía diarrea, está llena de grasa, es asquerosa, pero cuando tenía hambre la tenía que comer. En total salíamos dos horas al desayuno, una hora al medio día y a la tarde, si nos portábamos bien una hora más. Beatriz- EEUU 
Me impresiono el trato rígido de las policías mujeres (parece derecha, responda, hable), estábamos en época de dictadura, teníamos algunas reglas; como la formación a la madrugada, nos contábamos de a una, paradas contra la pared, mirando de costado a la compañera y diciendo el número que nos tocaba. Esto se hacía siempre con presencia de los miembros de la guardia y del 5 cuerpo del ejército que iba todas las mañanas a controlar. En la cárcel me decían cuando me levantaba, cuando me tenía que bañar, cuando comer, decidían todo por mí. Alicia- Argentina

Sin embargo el control no solo es ejercido sobre los tiempos y movimientos de las individualidades desde la disciplina, sino también desde una maquinaria institucional en ocasiones formal y en otras informal que se encarga de encuadrar un escenario dentro del cual las personas son clasificadas y -en esta tecnocracia carcelaria- administradas. Es lo que Foucault define como "Gubernamentalidad" en la medida que todas las individualidades juegan un rol activo y esta es la razón por la cual deben -desde la lógica del control poblacional- ser reguladas a través de diferentes técnicas.

Esta regulación tiene por objeto generar una interacción que contribuya a los fines del control, ya que un actor contribuya (a la interacción) es una expectativa legítima por parte de los demás actores, que así pueden conocer de antemano los límites dentro de los cuales el actor se comportara probablemente, y tiene el derecho virtual a esperar de él que se comporte de acuerdo con estas limitaciones. A la inversa, él debe comportarse como se espera de él, no por simple eficacia, sino por sentir que se trata de una manera conveniente de comportarse. Goffman (1991).

Esta conveniencia implica mayor o menor "riesgo de sufrir daño" dentro del ordenamiento carcelario.

En cada patio hay un "Pluma o Cacique", el pluma es la cabeza principal de cada patio, la "segunda" es quien está a cargo, si no está el pluma, pues alguien se podría 
tomar el poder a la brava. Decide sobre lo económico y lo disciplinario del patio ${ }^{4}$ y es "el vocero". Aunque supuestamente el vocero de los patios tendría que ser el "Delegado de DDHH" pero realmente no lo es... adentro es un mundo totalmente a parte. Se es pluma derrocando al anterior, haciendo "golpe de estado". El pluma debe responder al patio y a la cuota de la guardia para que no entre a requisar. Si es un tipo que le gusta golpear a la gente, que le gusta abusar de la comunidad del patio, entonces la gente se cansa y lo sacan o lo matan... no falta el inconforme que quiere armar la revolución, lo intenta y lo tiene lograr, porque si no lo logra, hay que tratar de salir vivo del patio...

Si los guardias están cansados del pluma, porque no da la cuota, Los mismos guardias se encargan de formar combos para sacarlo.

En los pasillos trabaja un Pasillero titular y otro segundo -que cumple el rol en caso de no estar el primero-. Están pendientes del pasillo, administran el recaudo de fondos provenientes de las líneas de teléfono ${ }^{6}$, líneas de droga $^{7}$ o cobros para manutención ${ }^{8}$ del pasillo, esto deben

4 Las sanciones que aplican los guardias son las legales, que le encuentren un teléfono, un arma. Un teléfono son seis meses de retención no validas, es decir, se redime por estudio 0 trabajo cierta cantidad de horas diarias, si se trabaja durante dos años completos, tiene un año ya ganado, la sanción repercute en eso. Si se tiene una sanción no se puede descontar y en cambio lo trabajado sirve para pagar la sanción. Harold-Colombia

5 El Delegado de DDHH es un funcionario que trabaja para la institución, pero adentro recibe órdenes del Pluma y trasmite lo que el pluma quiere. Tiene un chaleco gris que dice DDHH, hace asesorías jurídicas con la defensoría, anota, saca entrevistas... toda la información que recibe tiene que dársela al pluma.

6 Adentro del pasillo se venden los minutos y el que tiene línea debe pagar 150 mil pesos al mes (50 US)

7 Imagínese que la línea le pertenece a alguien, este se encarga de pagar la entrada, empaque y distribución, para esto paga una cuota al Pasillero o al Pluma, dependiendo de la importancia de la línea, puede haber una o más líneas. El pluma paga al guardia de turno y este a los demás mandos para evitar las requisas.

8 En mi pasillo costo ciento cincuenta mil pesos entrar un TV y un DVD "50 US" y por película 3 mil pesos (1 US), había que elegirlas bien y ojala que no fueran malas, porque si eran malas dolía.... 
pagarlo entre todos los que viven en el pasillo. Como parte de su equipo están los Allegados a la casa (son los guardaespaldas que coordinan las filas, ayudan a bajar las órdenes del pluma) y los Carros (quienes hacen el trabajo sucio a cambio de droga). Como en toda mafia, el Pluma y los Pasilleros eligen a su gente. Del patio para afuera están los guardias, ellos no entran al patio a menos que sea un operativo, lo deben, porque para eso hay unas reglas establecidas entre reclusos y guardias, ellos mandan de la reja para afuera, adentro manda el pluma "y la casa", que son la segunda y todos los pasilleros. Harold-Colombia

Hay una "comisaria" "una vez por semana, ofrecen paquetes de alimentos, atún, sardinas, macarela, valen 2US, si uno paga, puede tener algunos beneficios. Para eso los familiares u amigos deben hacer un depósito por Wester Unión desde cualquier parte del mundo, con el número del preso, ejemplo: quiero depositar 50 dólares al preso 5355 y asi queda registrado el dinero que tiene para comprar. Por ejemplo, Las "kiking" necesitan la droga, pero la cárcel no se las va a dar, a menos que tengan dinero, uno la ve temblando, o vomitando, lloran, sufren por la droga que necesitan. Muy pocas tienen familia que les mande dinero para poder comer o comprar cosas.

Un día yo no podía dejar de llorar y una amiga me pregunto si quería dormir, me dio media pastilla y dormí dos días, cuando me levante tenia taquicardia. Las pastillas se compran a los médicos o a la guardia. Todo es un negocio. Para poder comprar solo hay que decir que uno quiere dormir o que tiene esquizofrenia y le venden la morfina o las anfetaminas. Beatriz-EE.UU

Las autoridades formales dependían del director, pero en época de dictadura todos dependían del 5 cuerpo del ejército. Ellos estaban sometidos. Había un jefe del $\mathrm{SPB}$, director, y una responsable sargento. Una estructura verticalista. Al ser tan duro el sistema ellos hacían

9 Se refiere a una especie de comisión u organización que se encarga de la venta de diversos productos. Es administrada por la institución. 
todo lo que el ejército decía. En el comienzo del juicio a las juntas ${ }^{10}$ se produce una reforma muy grande adentro, sacan a todos los jefes del SPB, ponen civiles y comienza la conmutación de penas. Desaparece la milicada y de la excesiva dureza se pasa a un sistema más peligroso de lo que era antes.

En el modelo anterior había una represión muy clara, la tortura estaba naturalizada y permitida, y todo el control lo hacían los militares. En el nuevo modelo se pasa a un modelo de corrupción ${ }^{11}$, el SPB busca nuevos canales para ejercer el poder y convertirte en una cosa. ¿Queres estar mejor? Dame la guita y te lo consigo, pero yo soy el que manda. La fuerza de seguridad de agiorna a los momentos políticos y saca lo peor de si cuando les habilitan esa apertura, en épocas de dictadura serán más duros, en democracia más "blandos", pero si les abrís una puerta sacan lo que tienen adentro y empiezan a matar y reprimir. Alicia- Argentina

Es posible afirmar que pese a la diferencia no solo temporal, sino espacial de estos recuerdos, todos convergen en manifestar una lógica sumamente organizada en dos planos: uno en cuanto a la administración de la población; lo cual implica primordialmente la administración formal e informal de los castigos, "a través de sanciones que apoyan y sostienen la definición de reglas sociales que estimulan ciertas actividades y prohíben otras" Goffman (1991).

Tal como expresan los testimonios citados, sus vivencias en el encierro se desarrollan en un ordenamiento social en el

\footnotetext{
10 Viene a mi memoria que en el comedor, mientras escuchábamos que la policía del servicio decía "pobrecitos ellos no hicieron nada y los están juzgando", nosotras nos tomamos de las manos y llorábamos en silencio. Gozamos de ese momento histórico junto y tomado de las manos.

11 El SPB está formado para reprimir, para someter al otro, ¿si vos le sacas eso que le queda? Ahí comienza la corrupción más grave que yo he visto del SPB. Cuando hablo de corrupción, me refiero a que se cobraba, desde el cambio de celda hasta un régimen semi-abierto, eso valía el precio de una moto. Se canaliza la necesidad de reprimir en el delito. Uno de los jefes del SPB se afano toneladas de aceite y debíamos comer con grasa y para que no le encontraran el aceite, el tiro por las cañerías y por estas corría aceite y no agua.
} 
cual si siguiéramos literalmente los postulados de Goffman se entenderían que;

Si no se respetan las reglas o cuando ninguna regla parece aplicable, las personas ${ }^{12}$ dejan de saber cómo comportarse y de saber lo que deben esperar de otro. En el plano social, queda perturbada la integración de las acciones, con la consecuencia de desorganización social o desorden social. Al mismo tiempo, las personas padecen de anomia y de desorganización. Goffman (1991).

Sin embargo, esto podría aplicarse a la vida fuera de las instituciones totales, ya que como hemos venido afirmando, este ordenamiento social, no es un ordenamiento que surge naturalmente de la asociación voluntaria de individualidades, sino que es un ordenamiento social generado a los fines de controlar una población, por este motivo no es posible hablar de perturbación sobre el comportamiento de las personas, ya que es el ordenamiento carcelario el que configura un cambio de comportamiento en las mismas. Y con base en esto, la teoría de la posible anomia, es imposible de prever, ya que a falta de este impulso por parte del ordenamiento carcelario, las personas se remitirían a su comportamiento social, previo al ingreso a la vida carcelaria. En resumen, la vida carcelaria configura un ordenamiento social, en el cual las personas son introducidas y direccionadas acorde a los comportamientos que dicta el ordenamiento carcelario y en caso de no seguirlos, aparece la sanción. Y en este momento de aparición de la sanción, dentro de un espacio como la cárcel, que es un espacio sancionatorio, es cuando "el ordenamiento carcelario logra reproducir -para sus propósitos de control- las reglas del ordenamiento social de la vida en libertad. Acorde a esto la persona que infringen las reglas es un contraventor. Su infracción es un delito -dentro

\footnotetext{
12 Goffman usa la denominación "participantes", para designar a quienes interactuaran dentro del ordenamiento social, sin embargo, este ensayo considera más exacto hablar de personas y no participantes, ya que definirles como participantes implica otorgarles un voluntarismo participativo que no existe cuando las personas son privadas de su libertad y obligadas a desenvolverse en roles diferentes dentro de la institución total.
} 
del ordenamiento social de la cárcel-. El que infringe continuamente las reglas es un desviado" Goffman (1991) -que al igual que en la vida extra muros, se busca sancionar y apartar-.

Un segundo aspecto de convergencia entre los testimonios está relacionado al requerimiento por parte de la institución de pagos con el propósito de apaciguar los padecimientos que esta puede infligir. Estos pagos evidencian que "toda manifestación concreta de orden social debe producirse dentro de un contexto social más amplio -accionar de los funcionarios de la cárcel-. La acción que se extiende entre este orden y su medio social debe ser dirigida por una regulación integrada en este orden como tal" Goffman (1991) -accionar del preso funcionario-. Por otro lado, más allá de estos pagos económicos podemos hablar de los costos subjetivos que implica sobrevivir en el encierro, los cuales pueden llegar -sin duda- a ser mucho más altos.

Yo me he sentido avergonzada, me sentía como una basura todos los días de mi vida, llore todos los días en la cárcel, por eso nunca les he contado a mis hermanos lo que paso. Yo lloraba y lloraba, decía gracias a dios mi mama está muerta para no ver lo que estoy viviendo Solo saben algunas cosas mis hermanas que viven aquí. Beatriz - EE.UU

En la cárcel perdí muchas cosas de forma fea, todo lo que uno trabaja en cualquier momento se va, no lo digo por las cosas, sino por las personas, perdí a Linda (mi novia), teníamos una vida planeada y todo se pedio. Mis amigos más cercanos los perdí. No pude llorar la muerte de mi abuela y abuelo -que se murieron mientras yo estaba preso- y fueron con los que me crie toda la vida... en la cárcel uno aplaca todo, cualquier cosa que sucede produce rabia e impotencia. Harold-Colombia

Al salir se comprende la destrucción total que siente un ser humano, yo sentía que tenía la vida acomodada, me costó mucho volver a tener responsabilidades, en la cárcel me decían cuando me levantaba, cuando me tenía que bañar, cuando comer, decidían todo por mí. Cuando salí, fue un golpe horrible. Una persona cuando ingresa a la cárcel se rompe en mil pedazos y lo interesante es como 
se vuelve a armar en un ser humano. Cuando salí no era una persona completa, estaba limitada en todo.

Tengo una cuestión de que nunca pude volver a la unidad 4, no sé si volvería, pero no pude... Nunca les conté a mis compañeros mi historia, sin saber que hasta mi jefe lo sabía, me lo blanquearon tiempo después, mi hija aun no lo sabe... Yo perdí la inocencia, la alegría. En la cárcel no tenés ninguna posibilidad de resistir adentro. Lo más difícil ha sido la muerte de compañeras que se han suicidaron adentro, y el juicio oral por jueces de la dictadura, teníamos que ser un ejemplo de lo que no se debía hacer, ver a mi familia hecha pedazos fue muy duro, cuando me dieron la condena de 18 años ya estaba muerta ${ }^{13}$ Alicia - Argentina

Es posible afirmar que "si bien nadie vive en un permanente estado absoluto en su propia memoria, sino que se abren y cierran las cajas en las que se encuentran los restos del pasado" Sarlo (2007), abrir esas cajas del pasado saca a la luz la existencia y efectos de diversos traumas generados por experiencias de sufrimiento.

El trauma trastorna, desarticula el yo y genera huecos en la existencia; tiene efectos tardíos imposibles de controlar, sino con dificultad y, tal vez, imposibles de dominar plenamente. Causa una disociación de los efectos y las representaciones: el que lo padece siente, desconcentrado, lo que no puede representar o representa anestesiado lo que no puede sentir LaCapra(2005).

Y en este marco es dable afirmar que los mayores costos del encierro no son únicamente la vergüenza, rabia e impotencia quedan aún después de salir de la cárcel, sino también la indecibilidad no regulada -en términos de LaCapra- , la cual implica

13 "La cárcel sigue sirviendo para ocultar esa parte de la sociedad que no queremos ver, para degradar personas, para cosificar. Quitémonos la careta, la cárcel es únicamente para castigo. Yo no me olvido más un chico (Campos Lucero) que entro a los 18 años entero y se fue en libertad con una pierna y con un ojo menos, volvió, porque afuera tampoco le dieron muchas posibilidades y lo mataron adentro. Todos los presos han perdido una parte de su mente o de su cuerpo y eso te pinta de cuerpo entero para qué sirve la cárcel". 
situaciones en las que el pasado acosa y posee ${ }^{14}$, de modo que "las personas se ven entrampadas en la repetición compulsiva de escenas traumáticas, escenas en las que el pasado retorna y el futuro queda bloqueado o atrapado en un círculo melancólico y fatal que se retroalimenta" LaCapra (2005). Por esto cuando hablamos de victimas es necesario recurrir a sus memorias subjetivas, con el propósito de reconstruir desde el presente, sus pasados traumáticos, evidencias los dolores, traumas y angustias individuales para poder reconocerlos y abordarlos; ya que solo así, se pueden mermar los efectos del estigma interno que produce la cárcel en la subjetividad de quienes han soportado la desgracia de servir como insumo de una maquinaria destinada a degradar humanidades.

\section{Bibliografía}

Agamben, Giorgio (2000) Lo que queda de Auschwitz: el archivo y el testigo. Editorial Pre Textos. Valencia.

Benjamin, Walter (1989) Discursos interrumpidos I. Editorial Taurus. Buenos Aires.

Goffman, Erving (1991) "El orden de la interacción" en Los momentos y sus hombres. Editorial Paidós, Barcelona.

LaCapra, Dominick (2005) "Escribir la historia, escribir el trauma". Editorial Nueva Visión. Buenos Aires.

Levi, Primo (2015) "Los Hundidos y los salvados" Editorial Ariel. Buenos Aires.

Sarlo, Beatriz (2007) "Rescate de la Memoria" en Revista de la Universidad de Mexico. $\mathrm{N}^{\circ} 37$. UNAM. México.

Schütz, Alfred (1999) "El forastero. Ensayo de psicología social" en Estudios sobre teoría social. Editorial Amorrortu, Buenos Aires.

Traverso, Enzo (2001) "La historia Desgarrada Ensayo sobre Auschwitz y los intelectuales". Editorial Herder. Barcelona.

White, Hayden (2007) "el entramado histórico y el problema de la verdad" En: En torno a los límites de la representación. El nazismo y la solución final. Editorial Bernal. Quilmes.

\footnotetext{
14 Según LaCapra, en el actingout, los tiempos hacen implosión, como si uno estuviera de nuevo en el pasado viendo otra vez la escena traumática.
} 